\title{
Cluster, Divergence and Principal Component Analysis of Niger seed (Guizotia abyssinica (L. f.) Cass.) Genotypes
}

\author{
Birhanu Mengistu Aboye* \\ Holetta Agricultural Research Center, P.o. box 31, Holetta, Ethiopia
}

*Corresponding Authors: Birhanu Mengistu Aboye, Holetta Agricultural Research Center, P.o. box 31, Holetta, Ethiopia

\begin{abstract}
Niger seed is among the most important oilseeds in Ethiopian Agriculture. The genetic divergence of niger seed genotypes collected from diverse ecologies of Ethiopia were evaluated using simple lattice design based on 12 quantitative traits to assess the genetic diversity of Ethiopian niger seed genotypes using multivariate techniques. Cluster analysis grouped the genotypes into five distinct groups. Each group showed admixtures of accessions rather than traceable patterns of geographical origin. The highest inter cluster distance was observed between cluster $I V$ and $V(D 2=94.75)$ and the lowest divergence was observed between cluster II and IV $(D 2=19.80)$. The first five Principle components explained $81 \%$ of the total variation. The first component strongly influenced by days to flowering (-0.438) and number of head (0.377). Component two highly influenced by yield per plot (-0.542) and oil content (-0.532). Number of seed per head (0.623), number of primary branch and days to maturity (0.651) strongly influence component three, four and five respectively. Therefore, the study indicates the existence of genetic divergence among the tested genotypes and the possibility to identify divergent material with desirable agronomic features for the development of new superior niger seed cultivars through hybridization and selection by crossing accessions from different clusters.
\end{abstract}

Keywords: Cluster, Ethiopia, Genetic divergence, Niger seed, Principal component analysis

\section{INTRODUCTION}

Niger seed (Guizotia abyssinica (L.f.) Cass.) is the oldest indigenous oil crops with longest history of its cultivation in Ethiopia. Commercial niger seed is grown in Africa, India and Southeast Asia and the seed is imported around the world as a popular type of birdseed. The nutty test and pleasant odor; pale yellow oil of niger seed is the main source of edible oil for local consumption in Ethiopia and India (Adarsh et al., 2014).

The oil is used for cooking, lighting, anointing, painting and cleaning of machinery. Its oil is also a substitute for sesame oil for pharmaceutical purposes and can be used for soap-making. The press cake of niger seed can be used for animal feed, manure and fuel. It is also used in the making of soap and as carrier of scent in perfume industry (Ramadan, 2012). The oil extracted from the seed contains a high content of linoleic acid and essential fatty acid for mono-gastric animals including humans. Substances such as tocopherols, phospholipids and sterols obtained from niger seed provide protection against cardiovascular disorders and cancer (Kandel and Porter, 2002).

In addition to lack of high seed and oil yielding cultivars growing on marginal land with poor adoption of improved agronomic packages are the cause for low productivity of the crop in Ethiopia. The indeterminate growth habit, seed shattering, self-incompatibility, low yielding, lodging, less or low responsiveness to management inputs, disease, insect and parasitic weeds are the major production problems (Teklewold and Wakjira, 2004). The availability of limited genetic information and semi domesticated nature of the crop has been an obstacle for further improvement programs (Dempewolf et al., 2015). Systematic breeding efforts are necessary to evolve high seed and oil yielding niger seed cultivars. To achieve this, information about the nature and magnitude of genetic divergence in a given set of genotypes is essential for selection of diverse parents for hybridization which leads to wide range of gene recombination (Govindaraj et al., 2015).

Genetic divergence can play a key role and the basis for any crop improvement program to get maximum recombination in hybridization programs. The knowledge of genetic variation existing in germplasms are an important and essential aspect for initiating any crop breeding program because 
hybrids between lines of diverse origin generally display greater heterosis than those between closely related parents (Ekhlaque et al., 2016 and Bhandari et al., 2017 ).

Multivariate analysis such as Mahalanobis's $\mathrm{D}^{2}$ statistic, cluster and principal component analysis are important techniques for assessing the degree of divergence and the relative contribution of different characters to the total divergence. They are powerful tools in quantifying the degree of divergence in most crops. The $\mathrm{D}^{2}$ statistics measures the degree of diversification and determines the relative proportion of each component character to the total divergence (Sharam, 1996 and Shing and Chaudhary 1999).

For any successful breeding programs identification and knowledge of differences among genetic materials is critical for selection of appropriate resources adapted to specific environments. This crucial information obtained by evaluation of the available genotypes. However, genotypic characteristic of niger seed is still poorly understood because of the fact that information on this aspect is very limited. This has made the identification of the various genotypes and improvement of the crop very difficult.

Different researchers such as Yadav et al., (2012), Pulate et al. (2013), Kumar (2016) Goyal and Bisen, (2017) conducted genetic divergence study on niger seed genotypes. In Ethiopian niger seed genotypes, the information on these aspects is very scarce. Therefore, there is a need to generate information on the genetic divergence and identify traits for total variation among the niger seed genotypes both plant breeders and germplasms curators to optimize the use of the variability available. Even though niger seed provide significant contribution in the livelihood of Ethiopian farmers it is underutilized and considered as orphan oilseed. Hence, the present investigation was undertaken to study the genetic diversity of niger seed genotypes using genetic divergence $\left(\mathrm{D}^{2}\right)$, cluster and principal component analysis.

\section{MATERIAL AND MeTHODS}

\subsection{Experimental Materials and Design}

One hundred genotypes of niger seed were evaluated for some morphological traits under field conditions at Holetta Agricultural Research Center (HARC), Ethiopia. The experiment was arranged in a $10 \times 10$ simple lattice design. Planting was done in a plot of three rows with $2 \mathrm{~m}$ length and $0.3 \mathrm{~m}$ spacing between rows and $0.6 \mathrm{~m}$ distance between plots with $8 \mathrm{~kg} / \mathrm{ha}$ of seed rate. The distance between the blocks was maintained to $3 \mathrm{~m}$.

\subsection{Data Collection}

On the basis of ten randomly selected plants, data were recorded for number of primary branches (NPB), number of secondary branches (NSB), number of heads per plant (NH), number of seeds per head (NSH), number of seeds per plant (NSP) and plant height (PH). Days to $50 \%$ flowering (DF), days to $90 \%$ maturity (DM), grain filling period (GF), yield per plot (YPP), thousands seed weight (gm) and oil content were recorded on plot basis.

\subsection{Statistical Analysis}

Before proceeding to the multivariate analysis; the average mean value of genotypes were standardized by subtracting the mean and dividing by standard deviation. Genetic divergence analysis was computed based on multivariate analysis using Mahalanobis $\left(\mathrm{D}^{2}\right)$ statistic (Mahalanobis, 1936) using SAS software v9.3. Clustering of genotypes was performed by average linkage clustering method and the dendrogram was generated using MINITAB v14.

The $\mathrm{D}^{2}$ values obtained from pairs of clusters were considered as the calculated values of Chi-square $\left(\chi^{2}\right)$ and were tested for significance at $1 \%$ and $5 \%$ probability level against the tabulated values of $\chi^{2}$ for ' $\mathrm{P}$ ' degree of freedom, where $\mathrm{P}$ is the number of characters considered $(\mathrm{P}=12)$.

In order to highlight the resolving power of the ordination and to reduce a large set of variables to a small set and to assess the pattern of variations principal component analysis was performed. Following the criterion established by only PCs with Eigen values greater than one are considered as important.

\section{RESULT AND DISCUSSION}

\subsection{Cluster Analysis}

The cluster analysis has grouped the hundred niger seed genotypes into five distinct clusters based on their similarity (Figure 1). Raza et al. (2019) observed similar trend in diversity study of rapeseed and 
mustard germplasm using cluster analysis. Ahirwar et al. (2017) grouped 114 niger seed genotypes in to 8 clusters in which 90 of the genotypes were grouped in one cluster.

The distribution of accessions into different diversity classes was presented in table 1 . Members within a single cluster being considered as having more close relationships with each other than they are with those in significantly distant clusters. Each cluster comprises different number of genotypes and has unique characteristics. The current cluster analysis showed that the diversity presented in niger seed genotypes cannot be reduced into a few number of groups as it was done by Petros et al. (2007). According to their report 36 accessions of niger seed were grouped in to two major clusters. Conversely Parameshwarappa et al. (2009) grouped 52 niger seed accessions in to seven groups which is higher than our result. The divergence analysis by Goyal and Bisen (2017) grouped 71 niger seed genotypes into eleven clusters based on their genetic dissimilarity.

Even though, there are accessions grouped together from similar geographic origins; clustering of germplasms do not group exclusively on the basis of their origin rather genotypes from different origin grouped together due to their morphological differences. The evolutionary forces such as gene flow, genetic drift, mutation, migration, selection and germplasms exchange play roles in assigning the accessions to different clusters. These factors might be separated them into related but different gene pools. The result showed that selection of different traits in different areas might have been occurred. This finding was in agreement with the findings of other researchers Mekonnen and Wakjira, 2014 and Naznin et al., 2015. They found absence of association among different clusters established on agronomic traits and origin of genotypes in Ethiopian mustard and Brassica rape genotypes respectively.

Geographically distant accessions are grouped together; which indicates that accessions from different geographic origin might have similar genetic background. The random and independent clustering pattern and discordance among diversity patterns and geographical distribution of genotypes in this investigation showed that geographical isolation is not the only factor causing genetic diversity in niger seed. Therefore, for niger seed hybridization parental lines should be selected based on genetic diversity rather than the geographical distribution. The conflict of niger seed clustering and geographic origin was previously reported by different authors. Kumar (2016) clustered niger seed accessions from different geographic origins using Torcher clustering method; according to the result accessions from similar geographic origins clustered randomly and independently in to eleven separate clusters. Cluster analysis of forty niger seed genotypes based on their genetic similarity has grouped in to eleven clusters without considering their geographic origin (Pulate et al., 2013).

Table1. Distribution of 100 niger seed genotypes collected from different Geographic origins grouped into five clusters using 12 quantitative traits

\begin{tabular}{|c|c|c|c|}
\hline Cluster & $\begin{array}{l}\text { Number of } \\
\text { accessions }\end{array}$ & Accessions included in the cluster & $\begin{array}{l}\text { Source of } \\
\text { genotypes }\end{array}$ \\
\hline 1 & 65 & 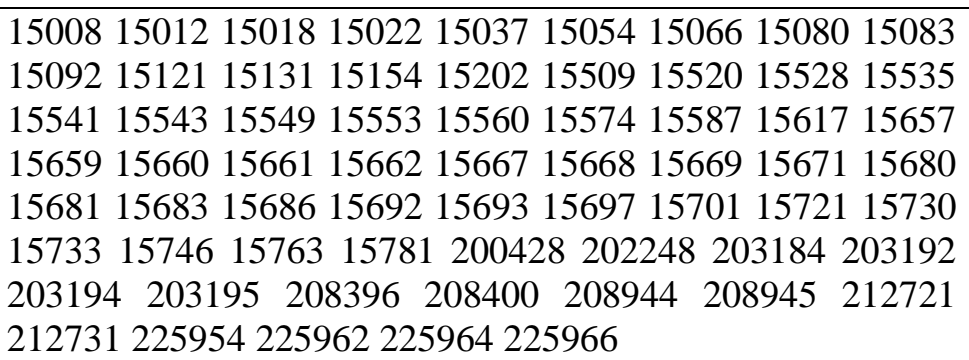 & Collections \\
\hline 2 & 30 & 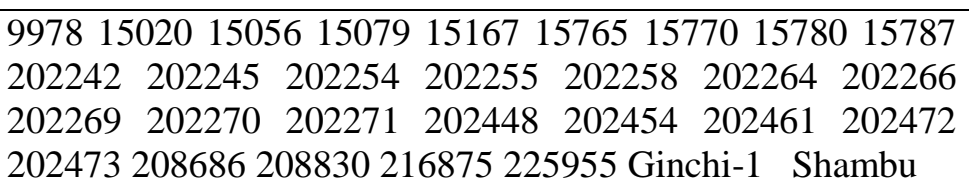 & $\begin{array}{l}\text { Collections } \\
\text { and } \\
\text { improved } \\
\text { varieties }\end{array}$ \\
\hline 3 & 1 & 15779 & Collections \\
\hline 4 & 3 & 151151513215622 & Collections \\
\hline 5 & 1 & 214217 & Collections \\
\hline
\end{tabular}





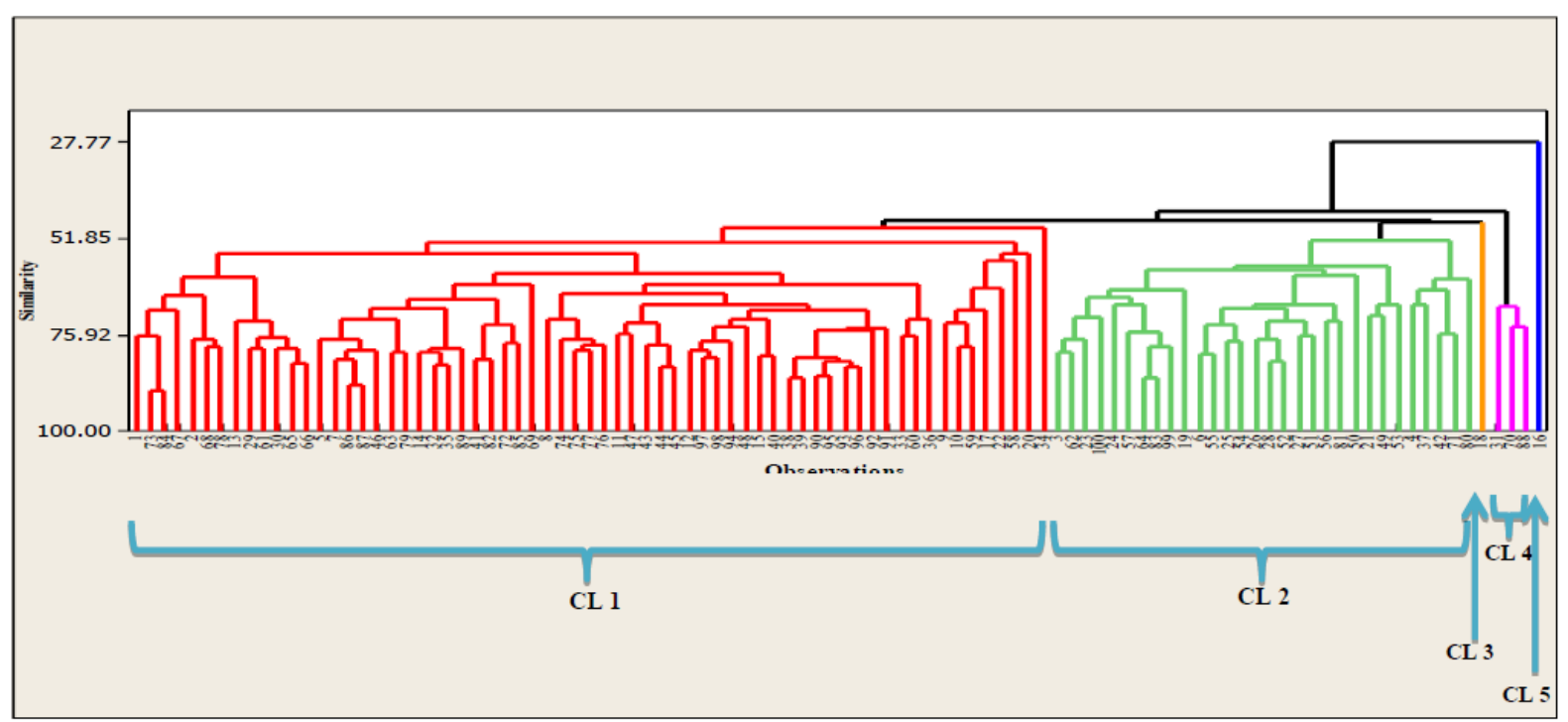

Figure1. Dendrogram showing relationship among 100 niger seed genotypes based on average linkage and Euclidean distance using the mean of 12 quantitative traits.

\subsection{Comparison of Clusters Mean}

The first cluster constitutes 65 accessions which were collected from the whole regions of Ethiopia. Accessions from Wellega and Shewa constituted more than $40 \%$ of the group. The whole accessions from Gonder except one were grouped in cluster I. The second cluster has 30 accessions; contains accessions from all populations except Gonder and Illubabor. In this group about $60 \%$ of the members were collected from Wollo and Gojjam. The geographic proximity of the two populations may favor the possible exchange of genetic material by human or natural factors. Improved varieties Ghinchi-1 and Shambu were grouped together in cluster two. The third and fifth clusters are solitary and they contain only single accessions. Similar trained were observed in the previous niger seed clustering studies. Pulate et al. (2013) they reported that seven solitary clusters were observed from the total eleven clusters. Kumar (2016) evaluated 71 niger seed accessions grouped into eleven clusters of which two of them are solitary clusters. Divergence analysis based on eleven important yield attributing traits grouped niger seed genotypes in to eleven clusters. Out of eleven clusters, three of them were solitary/monotypic (Goyal and Bisen, 2017).

According to the cluster mean values presented in table 2; the first cluster (C1) was explained by late flowering and late maturity. This cluster was also characterized by lowest mean value for the number of seed per plant and thousand seed weight. The second cluster (C2) was differentiated by early flowering, long grain filling period and short plant height. Good performance was observed for the number of heads and number of secondary branch. The third cluster (C3) which form separate cluster was characterized by shorter grain filling period and lower number of primary branch and lowest mean for number of secondary branch. But the cluster mean was among the top high yielder and top in thousand seed weight.

The fourth cluster (C4) was described by late maturing and long grain filling period. Whereas, this cluster had lowest performance for mean value for number of primary branch, number of heads, yield per plot, thousand seed weight and oil content. The average performance for number of seed per plant was also higher. Compared to the other clusters cluster five (C5) generally showed highest mean performance in most of the desirable traits. The cluster exhibited early maturity and short grain filling period, and highest number of primary branch, number of heads, number of seed per head, yield per plant and oil content. The cluster has also shorter days for flowering, long plant height and higher thousand seed weight. It is important to note that the superiority of a particular niger seed accessions in respect to a given character gets diluted by other genotypes that are related and grouped in the same cluster which are inferior or intermediary for that character in question. Likewise, wide variations in clusters mean have been reported by Ahirwar et al. (2017) in niger seed genotypes; Naznin et al., 2015 in Brassica rape; Mekonnen and Wakjira, 2014 in Ethiopian mustard. The occurrence of such 
variability among the clusters of great genetic value implies the need of developing suitable breeding strategy for niger seed improvement.

The cluster contributing maximum to the divergence was given emphasis for deciding the type of cluster for the purpose of selection and the choice of parents for hybridization. Therefore, clusters with highest mean value for the desired traits will be considered or selected as parents for hybridization or for other population improvement methods in future niger seed improvement.

Table2. Cluster mean values among the five clusters of 100 niger seed genotypes for 12 quantitative traits

\begin{tabular}{|l|l|l|l|l|l|l|}
\hline \multirow{2}{*}{ Traits } & \multicolumn{6}{|l|}{ Clusters } \\
\cline { 2 - 6 } & C1 & C2 & C3 & C4 & C5 & \\
\hline DF & 101.39 & 81.78 & 96.00 & 88.67 & 87.00 & 91.54 \\
\hline DM & 155.29 & 148.97 & 149.00 & 156.33 & 138.00 & 147.81 \\
\hline GFP & 53.90 & 67.18 & 53.00 & 67.67 & 51.00 & 56.27 \\
\hline PH & 133.93 & 120.47 & 132.00 & 127.33 & 133.00 & 129.85 \\
\hline NPB & 7.70 & 7.31 & 6.60 & 6.57 & 8.50 & 7.53 \\
\hline NH & 19.31 & 26.02 & 19.80 & 17.50 & 40.20 & 26.33 \\
\hline NSB & 10.45 & 15.23 & 8.00 & 8.40 & 22.30 & 13.99 \\
\hline NSH & 40.31 & 63.80 & 66.25 & 149.67 & 102.35 & 68.18 \\
\hline NSPP & 76.60 & 147.64 & 133.10 & 245.50 & 399.80 & 189.29 \\
\hline YPP & 102.25 & 104.10 & 104.17 & 101.00 & 105.10 & 103.90 \\
\hline TSW & 1.71 & 2.00 & 3.00 & 1.70 & 2.40 & 2.28 \\
\hline OC & 33.95 & 36.53 & 36.90 & 30.30 & 37.70 & 36.27 \\
\hline
\end{tabular}

$\mathrm{DF}=$ days to flowering, $\mathrm{DM}=$ days to maturity, $\mathrm{GFP}=$ Grain filling period, $\mathrm{PH}=$ plant height, $\mathrm{NH}=$ number of heads, $\mathrm{NPB}=$ Number of primary branch, NSB=Number of secondary branch, NSH $=$ number of seed per head, NSPP $=$ Number of seed per plant, YPP=yield per plot, TSW=Thousand seed weight and $\mathrm{OC}=$ oil content.

\subsection{Distance Among Clusters (D2 Analysis)}

The standardized Mahalanobis's $\mathrm{D}^{2}$ statistics showed existence of high genetic distance among the five clusters. Out of 10 possible pairs of clusters, differences between eight pairs were highly significant $(\mathrm{P}<0.01)$ and one pairs were significant $(\mathrm{P}<0.05)$ while one pair was non-significant (Table $3)$. The maximum distance was found between cluster four and five $\left(D^{2}=94.75\right)$. Cluster four constitutes three accessions each of them comprise from Illubabor, Shewa and Wellega regions; While, cluster 5 constitute accession from Gonder. The geographic divergence may favor the accumulation of contrasting alleles between the two groups which increase genetic dissimilarity between the clusters. These suggesting that the genotypic materials with maximum inter cluster distance may be used as parents for hybridization program to develop desirable varieties; because crosses between genetically divergent lines will generate heterotic segregates' or broad spectrum of variability in subsequent generations (Khodadadi et al., 2011 and Afroz et al., 2013).

Table3. Pair-wise generalized squared distances $\left(D^{2}\right)$ values between clusters constituting 100 niger seed genotypes

\begin{tabular}{|l|l|l|l|l|l|}
\hline Clusters & 1 & 2 & 3 & 4 & 5 \\
\hline 1 & & & & & \\
\hline 2 & $15.92 \mathrm{~ns}$ & & & & \\
\hline 3 & $44.86^{* * *}$ & $36.69^{* * *}$ & & & \\
\hline 4 & $27.69^{* *}$ & $19.80^{* *}$ & $69.15^{* * *}$ & & \\
\hline 5 & $67.79^{* * *}$ & $59.35^{* * *}$ & $64.45^{* * *}$ & $94.75^{* * *}$ & \\
\hline
\end{tabular}

$\mathrm{ns}=$ non-significant $\mathrm{P}>0.05, *=$ significant at $\mathrm{P} \leq 0.05, * *=$ significant at $\mathrm{P} \leq 0.01, * * *=$ highly significant at $\mathrm{P}<0.001$

The second most divergent clusters was cluster three and four $\left(\mathrm{D}^{2}=69.15\right)$. Cluster three comprises only one accession from Wollo. The lowest divergence was observed between cluster one and two $\left(\mathrm{D}^{2}\right.$ $=15.92$ ), which shows the presence of less genetic variability or diversity between this clusters. The present study recorded lowest $\mathrm{D}^{2}$ values when we compared with the previous study (Parameshwarappa et al., 2009); the highest value they reported was $\mathrm{D}^{2}=252.150$ which is twofold 
higher than the current report. But almost equal lowest $\mathrm{D}^{2}$ value (15.92) was observed. For crossing parents selection should be from clusters with highest genetic distance to obtain highest genetic recombination and transgressive segregates' in the subsequent generation. Crossing of parents from clusters described by significant distances will give maximum genetic segregation and genetic recombination (Pulate et al., 2013). Increasing parental distance mean great number of contrasting alleles at the desired loci therefore, the extent of these loci recombine in the F2 and F3 generation following a cross of distantly related parents has a high potential. According to the present investigation crossing of accessions from cluster four and five followed by cluster three and four would give rise to maximum recombination and segregation of the progenies. However crossing of low distance clusters (cluster 1 and 2) might not give higher heterotic value in F1 and narrow range of variability in the segregating F2 population.

It is valuable to note that in calculating cluster mean, the superiority of a particular accession with respect to a given character could get diluted by other accessions that are grouped in the same cluster but are inferior or intermediate for the character in question. Hence apart from selecting genotypes from the clusters which have higher inter-cluster distance for hybridization one can also think of selecting parents based on the extent of divergence in respect to a character of interest.

\subsection{Principal Component Analysis}

Principle component analysis is really a reliable tool for successfully selection of parents in breeding program of any crop (Venujayakanth et al., 2017). In order to reduce a large set of variables to a small set and to assess the pattern of variations; a well-known method of dimension reduction, principal component analysis was done by considering all the 12 variables simultaneously. Five of the 12 principal components accounted for more than $81 \%$ the total variation (Table 4). The phenotypic variation reflect in the principal component analysis cannot be explained in terms of few principal components. However previous studies on niger seed genotypes reported different percentage with similar number of PCs. According to Kumar (2016) report on 71 niger seed accessions; $71.82 \%$ of the total variation was explained by five components which are below the present finding. Conversely, Pulate et al. (2013) reported that $96.23 \%$ of variation was contributed by the first five principle components.

Table4. Eigen value, percentage, cumulative variances and Eigen vectors on the first five principal components for 12 traits in 100 niger seed genotypes

\begin{tabular}{|l|l|l|l|l|l|}
\hline Traits & PC1 & PC2 & PC3 & PC4 & PC5 \\
\hline DF & $\mathbf{- 0 . 4 3 8}$ & -0.142 & 0.184 & 0.006 & 0.051 \\
\hline DM & -0.306 & 0.001 & 0.033 & 0.179 & $\mathbf{0 . 6 5 1}$ \\
\hline GFP & $\mathbf{0 . 3 5 6}$ & 0.186 & -0.216 & 0.119 & $\mathbf{0 . 3 9 4}$ \\
\hline PH & -0.265 & -0.021 & $\mathbf{0 . 4 3 3}$ & -0.322 & -0.206 \\
\hline NPB & 0.015 & $\mathbf{- 0 . 4 7 4}$ & 0.258 & $\mathbf{- 0 . 4 6 2}$ & $\mathbf{0 . 3 0 0}$ \\
\hline NH & $\mathbf{0 . 3 7 7}$ & -0.022 & -0.113 & -0.350 & 0.135 \\
\hline NSB & $\mathbf{0 . 3 2 8}$ & $\mathbf{- 0 . 3 5 2}$ & -0.017 & -0.276 & 0.149 \\
\hline NSH & 0.223 & 0.123 & $\mathbf{0 . 6 2 3}$ & $\mathbf{0 . 3 5 2}$ & 0.088 \\
\hline NSPP & $\mathbf{0 . 3 4 8}$ & 0.059 & $\mathbf{0 . 4 8 6}$ & 0.162 & 0.125 \\
\hline YPP & 0.005 & $\mathbf{- 0 . 5 4 2}$ & -0.031 & $\mathbf{0 . 3 5 8}$ & -0.136 \\
\hline TSW & 0.302 & -0.019 & 0.094 & -0.031 & $\mathbf{- 0 . 4 4 9}$ \\
\hline OC & 0.079 & $\mathbf{- 0 . 5 3 2}$ & -0.129 & $\mathbf{0 . 3 9 8}$ & -0.049 \\
\hline Eigen value & 4.275 & 2.021 & 1.472 & 1.142 & 0.909 \\
\hline Proportion & 0.356 & 0.168 & 0.123 & 0.095 & 0.076 \\
\hline Cumulative & 0.356 & 0.525 & 0.647 & 0.742 & 0.818 \\
\hline
\end{tabular}

PC1, PC2, PC3, PC4 and PC5 = Principal component 1, 2, 3, 4 and 5 respectively; DF=days to flowering, $\mathrm{DM}=$ days to maturity, $\mathrm{GFP}=\mathrm{Grain}$ filling period, $\mathrm{PH}=$ plant height, $\mathrm{NH}=$ number of heads, $\mathrm{NPB}=$ Number of primary branch, NSB=Number of secondary branch, NSPP $=$ Number of seed per plant, YPP=yield per plot, TSW=Thousand seed weight, $\mathrm{OC}=$ oil content.

The contribution of morphological traits in the loading plot showed that number of head, grain filling period, number of seed per plant, days to flowering and days to maturity have strongly influenced the 
loading plot of the first component. Whereas yield per plot, number of primary branches and oil content have weak influence. Principal component two strongly influenced by yield per plot, number of primary branches and oil content. However, weak influence for loading plot of the second component were observed by number of heads, thousand seed weight, number of seeds per plant, days to maturity and plant height (Figure 2). The Positive and negative loading shows the presence of positive and negative correlation trends between the components and the variables.

In our experiment the data revealed that traits with high contribution in the first component indicate that they contributing maximum towards divergence. Therefore the divergence in the present materials due to these traits will offer good scope for improvement of niger seed through selection of parents for crossing. It was concluded that the germplasms exhibited a wide range of variability for most of the traits. Some genotypes possessed desirable genes for more than one character and hence could be utilized directly or included in hybridization programs for variety development. Genotypes will be selected on the basis of special objectives and no common criteria can be considered for selection of genotypes.

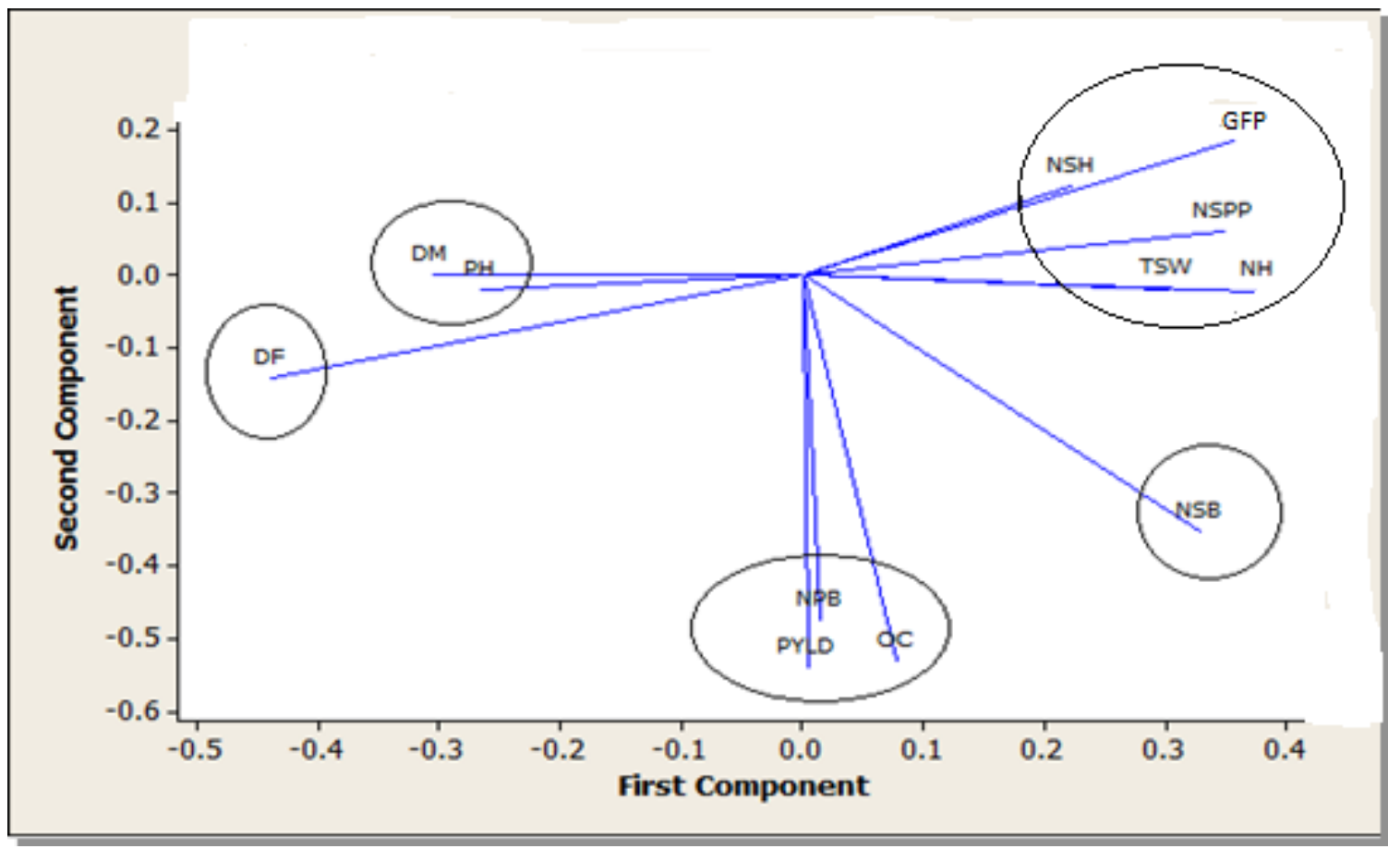

$\mathrm{DF}=$ days to flowering, $\mathrm{DM}=$ days to maturity, $\mathrm{GFP}=$ Grain filling period, $\mathrm{PH}=$ plant height, $\mathrm{NH}=$ number of heads, $\mathrm{NPB}=$ Number of primary branch, $\mathrm{NSB}=$ Number of secondary branch, $\mathrm{NSPP}=$ Number of seed per plant, YPP=yield per plot, TSW=Thousand seed weight, OC $=$ oil content.

Figure 2 Loading plots of the first two principal components showing the contribution of different morphological traits to the total variation by the two components

In breeding programs, genetic divergence analysis aims to identify parents for the generation of populations with genetic variability and consequent genetic gain in successive selection cycles. In selecting the most divergent parents, it is advisable to select, within each group, parents with higher averages in relation to those characters to be improved, with the aim of achieving the maximum concentration of favorable alleles, according to the selection objectives.

\section{CONCLUSION}

Genetic distance is very important for hybridization program to get better yield and best recombinant parents. In the present study the multivariate analyses of genetic divergence among genotypes have resulted in the formation of five clusters and have shown the presence of genetic variability for further selection and breeding. We could also found that geographical diversity could not necessarily be an index of genetic variability to group genotypes in to different clusters. Genetic distances among most clusters were significant from which selection of parents may be made for crossing in order to obtain genetic recombination. Genotypes in clusters IV and V possess highest cluster distance and thus; the 
genotypes of these two clusters hold great promise as parents in hybridization program to obtain promising heterotic expression in F1 and may create considerable variability in the segregating populations. Significant differences were observed among the genotypes for various traits indicating the scope for selection from diverse genotypes for desired traits.

\section{ACKNOWLEDGMENT}

The author would like to thank Ethiopian Institute of Agricultural Research for financial support to conduct the experiment and Holetta Agricultural Research Center National High and Midland oilseeds technicians for their support.

\section{REFERENCES}

[1] Adarsh MN, Poonam K, Shilpa D (2014). A review of Guizotia abyssinica: A multi-purpose plant with an economic prospective. Journal of Industrial Pollution Control 30(2): 277-280.

[2] Afroz S. Noman MS. Hossain MS. Mamun AA. Howlader N. Ara S. (2013). Multivariate Analysis Approach to Select Parents for Hybridization Aiming at Yield Improvement in Cucumber (Cucumis sativus L.). Journal of Environmental Science and Natural Resources 6(1): 33-36.

[3] Ahirwar AD, Tiwari VN, Rai GK, Ahirwar SK (2017). Analysis of genetic divergence in Niger (Guizotia abyssinica (L.F.) Cass.) germplasm. Plant Archives 17: 115-117.

[4] Bhandari HR, Bhanu AN, Srivastava K, Singh MN, Shreya (2017). Assessment of genetic diversity in crop plants an overview. Advance Plants Agricultural Research. 7(3): 00255

[5] Dempewolf H, Tesfaye M, Teshom A, Bjorkman AD, Andrew RL, Scascitelli M, Black S, Bekele E, Engels JM, Cronk QC, Rieseberg LH (2015). Patterns of domestication in the Ethiopian oilseed crop niger seed (Guizotia abyssinica). Evolutionary Applications 8(5): 464-475.

[6] Ekhlaque Ahmad, Munish Kumar Singh A, Paul A, Ansari M, Singh DN (2016). Genetic Studies of Yield and Yield Component of Niger (Guizotia Abyssinica Cass.) in Rain fed Condition of Western Plateau of Jharkhand. International Journal of Tropical Agriculture 34(4):1127-1133

[7] Fida Hussain, Muhammad Rafiq, Maria Ghias, Rizwana Qamar, Muhammad Khurram Razzaq, Amir Hameed, Sajida Habib, Hafiz Saad Bin Mustafa (2017). Genetic Diversity for Seed Yield and its Components Using Principal Component and Cluster Analysis in Sunflower (Helianthus annuus L.). Life Science Journal 14(5): 71-78.

[8] Govindaraj M, Vetriventhan M, Srinivasan M. (2015) Importance of genetic diversity assessment in crop plants and its recent advances: an overview of its analytical perspectives. Hindawi Publishing Corporation Genetics Research International. http://dx.doi.org/10.1155/2015/431487

[9] Goyal VK, Bisen R (2017). Assessment of genetic divergence in niger seed germplasm. Indian Journal of Crop Science. 5(4): 1482-1485.

[10] Kandel H, Porter P (2002). Niger seed (Guizotia abyssinica (L.f.) Cass). Production in North West Minnesota. University of Minnesota extension service (eds).

[11] Khodadadi M. Fotokian MHS. Miransari M. 2011. Genetic diversity of wheat (T. aestivum L.) genotypes based on cluster and principal component analysis for breeding Strategies. Australian Journal of Crop Science 5(1): 17-24.

[12] Kumar V (2016). Morphological characterization and genetic analysis for yield and quality traits in niger seed. MSc Thesis College of Agriculture, Jabalpur Jawaharlal Nehru Krishi Vishwa Vidyalaya Jabalpur, MP.

[13] Mahalanobis PC (1936). On generalized distance in statistics. Proceeding of the National Institute of Science of India 2(1): 49-55.

[14] Mekonnen TW, Wakjira A. (2014). Multivariate analysis of genetic divergence among Ethiopian mustard (Brassica carinata A. Braun) landraces in Ethiopia. International Journal of Genetics and Molecular Biology 6(4):37-45.

[15] Naznin S, Kawochar MA, SUltana S, Zeba N, Bhuiyan SR (2015). Genetic divergence in Brassica rape L. Bangladesh Journal of Agricultural Research 40(3): 421-433.

[16] Parameshwarappa SG, Salimath PM, Palakshappa MG (2009). Assessment of genetic diversity in niger seed (Guizotia abyssinica (L.F.) Cass). Karnataka Journal of Agricultural Sciences 22(4): 879-880.

[17]Petros Y, Merker A, Zeleke H (2007). Analysis of genetic diversity of Guizotia abyssinica from Ethiopia using inter simple sequence repeat markers. Hereditas 144(1): 18-24.

[18] Pulate SC, Patil HS, Patil MR (2013). Multivariate analysis of genetic among niger seed genotypes in relation to seed oil quality traits. The Bio scan. 8(3): 829-833. 
[19] Ramdan MF (2012) Functional properties, nutritional value and industrial applications of niger oilseeds (Guizotia abyssinica Cass.). Critical reviews in food science and nutrition 52:1-8.

[20] Raza I, Masood MA, Abid S (2019). Study of genetic diversity in rapeseed and mustard germplasm by using cluster analysis. Journal of Applied Biotechnology and Bioenergy 6(5):242-245. DOI: 10.15406/jabb.2019.06.00199.

[21] SAS Institute (2010). SAS/STAT Guide for Personal Computers, Version 13.1 editions. Cary, N.C., SAS Institute Inc.

[22] Sharam S (1996). Applied multivariate techniques. John Wiley and Sons, Inc., New York, U.S.A., 493P.

[23] Singh RK, Chaundhary BD (1999). Biometrical methods in quantitative genetics analysis. Kalyani publishers, New Delhi. P. 73.

[24] Teklewold A, Wakjira A (2004). Seed filling and oil accumulation in niger seed (Guizotia abyssinica (L.f.) Cass). Sinet Ethiopian Journal of Science 27(1): 25-32.

[25] Venujayakanth B, Dudhat AS, Swaminathan B, Anurag ML (2017). Assessing Crop Genetic Diversity using Principle Component Analysis: a review. Trends in Biosciences 10 (2): 523-528.

[26] Yadav S, Hussain Z, Suneja P, Nizar MA, Yadav SK, Dutta M (2012). Genetic divergence studies in niger seed (Guizotia abyssinica) germplasm. Biomass and Bioenergy 44: 64-69.

Citation: Birhanu Mengistu Aboye, “ Cluster, Divergence and Principal Component Analysis of Niger seed (Guizotia abyssinica (L. f.) Cass.) Genotypes” International Journal of Research Studies in Agricultural Sciences (IJRSAS), 2021; 7(2), pp. 17-22, https://doi.org/10.20431/2454-6224.0702003

Copyright: (C) 2021 Authors. This is an open-access article distributed under the terms of the Creative Commons Attribution License, which permits unrestricted use, distribution, and reproduction in any medium, provided the original author and source are credited. 